\title{
SUR LA MESURE DES DISTANCES PAR
}

TELEMETRIE LASER

\author{
R. BOUIGUE \\ Université de Toulouse, France
}

Résumé. On fait une analyse des différents procédés de mesure des distances dans le système solaire et dans son voisinage en vue de mettre en évidence les différentes corrections que ces mesures peuvent nécessiter.

Une application particulière faite aux distances obtenues par télémètrie-laser montre que ces corrections ne sont plus actuellement négligeables. 